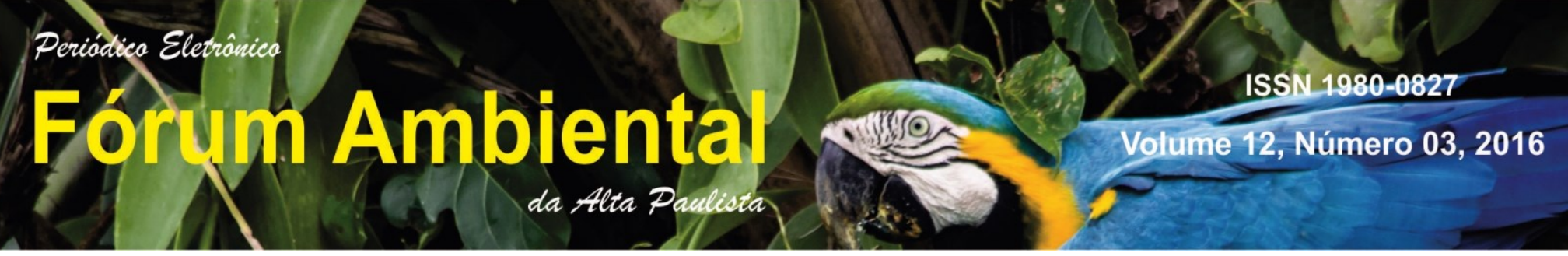

\title{
Concentração de matéria orgânica nas águas da porção urbana da bacia hidrográfica do Córrego do Limoeiro
}

Concentration of organic matter in the waters of the urban portion of the watershed of the Stream of Limoeiro

Concentración de materia orgánica en las aguas de la parte urbana de la cuenca hidrográfica del Arroyo del Limoeiro

Gabriel Coimbra Rabelo Graduação em Engenharia Ambiental, UNESP - FCT, Brasil. gabriel.crsp@gmail.com

José Biscaíno Neto Graduação em Engenharia Ambiental, UNESP - FCT, Brasil. josebiscainoneto@hotmail.com

Rosane Freire Professora Assistente Doutora, UNESP - FCT, Brasil. rosane@fct.unesp.br 


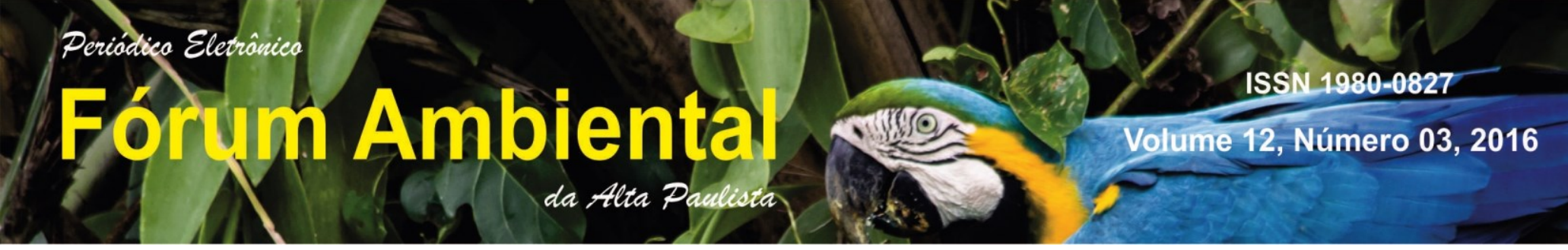

\section{RESUMO}

Realizou-se o presente trabalho na bacia hidrográfica do Córrego do Limoeiro, compreendido na porção urbana do município de Presidente Prudente - SP, durante o período de novembro/2014 a março/2016, para analisar a concentração de matéria orgânica presente nos cursos d'água da bacia. Foram selecionados cinco pontos amostrais, onde foram efetuadas coletas bimestrais, para aferições dos principais indicadores de poluição orgânica: Demanda Bioquímica de Oxigênio (DBO), Oxigênio Dissolvido (OD) e Coliformes Termotolerantes. Percebeu-se que os parâmetros analisados tiveram variações espaciais expressivas, atribuído as fontes de poluição. Por meio dos parâmetros analisados verificou-se uma situação crítica em relação ao Coliformes Termotolerantes, sobretudo, no ponto próximo aos estabelecimentos comerciais e no ponto perto ao lançamento dos efluentes dos frigoríficos e curtume. Constatou-se que as ações antrópicas estão degradando fortemente as águas da bacia hidrográfica do Córrego do Limoeiro. Há necessidade de investimentos e de medidas para reverter esse cenário que conduz a uma iminente escassez hídrica.

PALAVRAS-CHAVE: Qualidade da água. Poluição hídrica. Concentração de matéria orgânica.

\section{ABSTRACT}

The present work was developed in the watershed of the Steam of Limoeiro, understood in the urban part of the municipality of Presidente Prudente - SP, during the period from november/2014 to march/2016, to analyze the concentration of organic matter present in the water courses of the basin. Five sampling points were selected, which were made bimonthly samplings, to measurements of the main indicators of organic pollution: Biochemical Oxygen Demand (BOD), Dissolved Oxygen (DO) and Thermotolerant Coliforms. One can see that the parameters had significant spatial variations attributed the pollution sources. Through the parameters analyzed there was a critical situation regarding Thermotolerant Coliforms, especially at the point near the shops and at the point near the launch of the effluent from refrigerators and tannery. It was noted that human actions are degrading strongly the waters of the watershed of the Stream of Limoeiro. There is a need for investment and measures to reverse this scenario leading to an imminent water scarcity.

KEYWORDS: Water quality. Water pollution. Concentration of organic matter.

\section{RESUMEN}

El presente trabajo se llevó a cabo en la cuenca hidrográfica del Arroyo del Limoeiro, entendida en la parte urbana del municipio de Presidente Prudente - SP, durante el período comprendido entre noviembre/2014 a marzo/2016, para analizar la concentración de materia orgánica en los cursos de agua de la cuenca. Cinco puntos de muestreo fueron seleccionados, que se realizaron muestreos bimensuales, para las mediciones de los principales indicadores de contaminación orgánica: Demanda Bioquímica de Oxigeno (DBO), Disuelta Oxigeno (DO) y Coliformes Termotolerantes. Se observa que los parámetros analizados tenían variaciones espaciales significativas atribuidas a las fuentes de contaminación. Mediante los parámetros analizados se encontró una situación crítica con respecto a los Colifomes Termotolerantes, especialmente en el punto cerca de las tiendas y en el punto cerca de la liberación de efluentes de los frigoríficos y curtiembre. Se observó que las acciones humanas están degradando fuertemente las aguas de la cuenca hidrográfica del Arroyo del Limoeiro. Hay una necesidad de inversión y medidas para revertir este escenario conduce a una escasez de agua inminente.

PALABRAS CLAVE: Calidad del agua. Contaminación del agua. Concentración de materia orgánica. 


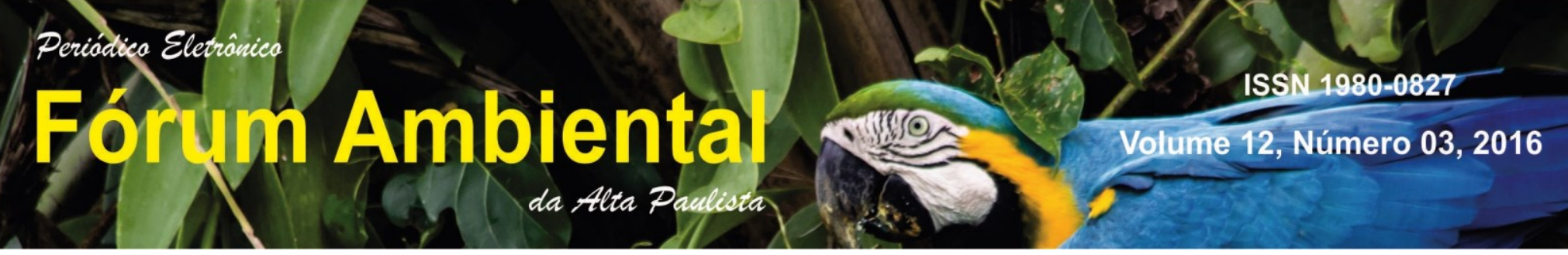

1

INTRODUÇÃO

A poluição de corpos hídricos superficiais é um dos maiores problemas ambientais em todo o mundo, provocando efeitos negativos para a saúde ambiental e prejudicando a manutenção das condições básicas da qualidade d’água para seus múltiplos usos (LEITE, 2004).

O crescimento das cidades tem sido responsável pelo aumento da pressão das atividades antrópicas sobre os recursos naturais. Em relação aos recursos hídricos, a poluição dos corpos d'água é causada pela introdução de matéria e/ou energia modificando as características da água, podendo, até mesmo, interferir na biota. A resposta dos corpos hídricos ao lançamento de despejos industriais e domésticos varia em função de suas características físicas, químicas e biológicas e da natureza das substâncias despejadas (NAGALLI E NEMES, 2009).

Nesse cenário, a poluição compromete, inclusive, um dos usos prioritários das águas: 0 abastecimento da população, principalmente nos corpos hídricos próximos das cidades. Atualmente, água tem que ser captada em regiões cada vez mais distantes para atender aos usos prioritários, além de passar por processos de tratamento cada vez mais complexos e dispendiosos, encarecendo os serviços de saneamento e tornando o recurso cada vez mais escasso (DINIZ, 2006).

As fontes de poluição da água são classificadas em duas categoriais: pontuais e difusas. As fontes pontuais podem ser relacionadas a um ponto específico de descarga. Enquanto que as fontes difusas se caracterizam por apresentarem ampla área de contribuição provindo de atividades que depositam poluentes de maneira esparsa, podendo alcançar os corpos d'água de forma intermitente, associados aos períodos de chuva (IPT, 2000).

Devido ao atual desenvolvimento técnico, as fontes pontuais são mais fáceis de serem subtraídas. Na maioria dos países desenvolvidos, grande atenção tem sido dada á poluição difusa, por conta de os lançamentos pontuais já terem sido equacionados. Entretanto, nos países em desenvolvimento, ainda se faz necessária a adoção de ações que promovam o controle da poluição pontual originária das cidades e indústrias (BARROS, 2008).

A poluição hídrica de maior representatividade em volume e em concentração é de característica orgânica, principalmente por estar ligada à composição dos esgotos domésticos. Durante o processo de estabilização da matéria orgânica presente na água do corpo receptor, Oxigênio Dissolvido (OD) é consumido por meio do metabolismo dos microrganismos decompositores, levando frequentemente à depleção deste elemento essencial a vida (LEITE, 2004).

O parâmetro mais importante no controle das atividades poluidoras, sendo utilizado na avaliação de eficiência de Estações de Tratamento de Esgoto (ETEs) e na definição de limites de descarte de matéria orgânica, é a Demanda Bioquímica de Oxigênio (DBO). Se trata de um indicador indireto de matéria orgânica, mensurado pela quantidade de oxigênio necessária para os microrganismos estabilizaram à matéria orgânica presente (LEITE, 2004).

Enquanto o esgoto sanitário causa poluição orgânica e bacteriológica, principalmente por coliformes presentes nas fezes humanas, o industrial geralmente produz a poluição química. $O$ efluente industrial, além das substâncias presentes na água de origem, contém impurezas 


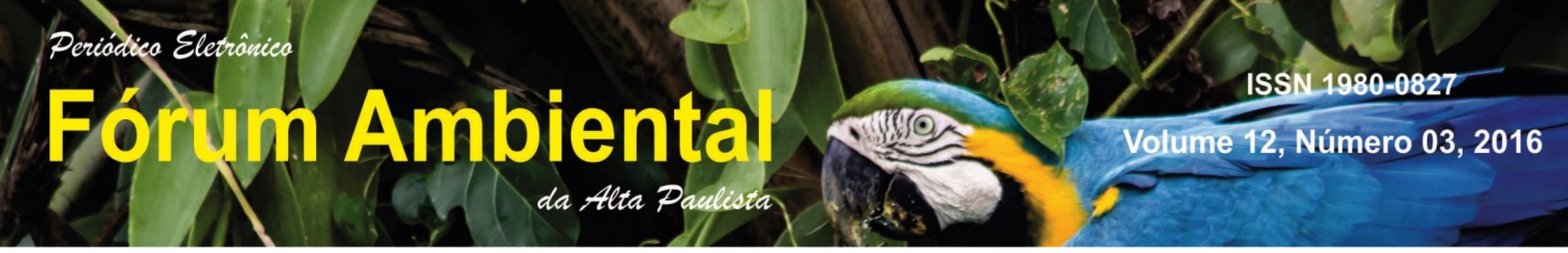

Para atingir o objetivo proposto, o desenvolvimento desse trabalho foi estabelecido por meio de uma série de atividades, tais como: caracterização a área de estudo, levantamento pluviométrico, campanhas amostrais e a realização dos ensaios laboratoriais e análise dos dados, como segue.

\subsection{CARACTERIZAÇÃO DA ÁREA DE ESTUDO}

Com a finalidade aprimorar os conhecimentos a respeito da área de estudo foram realizadas buscas bibliográficas nas principais bases digitais (Scielo, Science Direct, Bibliotecas Digitais, etc.) no qual permitiram caracterizar a área de estudo, em função da densidade populacional, geologia, geomorfologia, climatologia, vegetação e uso e ocupação do solo.

\subsection{DADOS PLUVIOMÉTRICOS}

Foram coletados dados da Estação Meteorológica da FCT - UNESP com a finalidade de analisar o comportamento da quantidade de chuva precipitada ao longo do período de coleta, ou seja, de novembro/ 2014 a março/ 2016.

\subsection{LEVANTAMENTOS DE CAMPO}

Foram escolhidos 5 pontos amostrais estratégicos, envolvendo, principalmente, a área urbanizada da bacia hidrográfica do Córrego do Limoeiro. Esses pontos foram selecionados considerando as potenciais fontes de poluição bem como o aspecto de acessibilidade. A Figura 1 mostra a distribuição espacial dos pontos amostrais na limitação da bacia, sobreposta a uma imagem Landsat 8 de 15/01/2015 (USGS, 2015).

Os pontos P1 e P2 situam-se no Córrego Colônia Mineira, respectivamente, no bairro Parque Residencial São Lucas e no bairro Jardim Belo Horizonte. O P1 se situa o mais próximo da nascente, o mesmo foi escolhido de forma estratégica para avaliar a qualidade da água próxima a nascente. O P2 foi escolhido por estar em uma área residencial podendo, dessa forma, verificar a influência da urbanização na alteração da qualidade da água. $O$ córrego se encontra com leito impermeabilizado, como apresentado na Figura 2. 


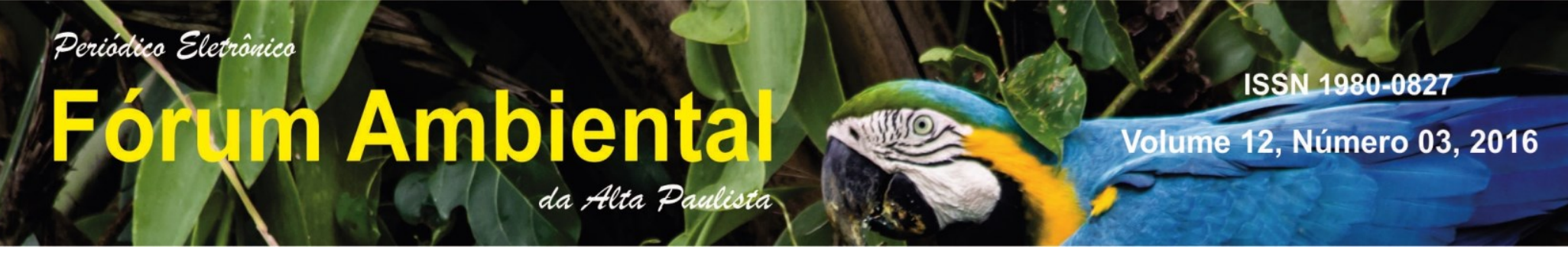

Figura 3: Pontos de amostragem. A) P3; B) P4
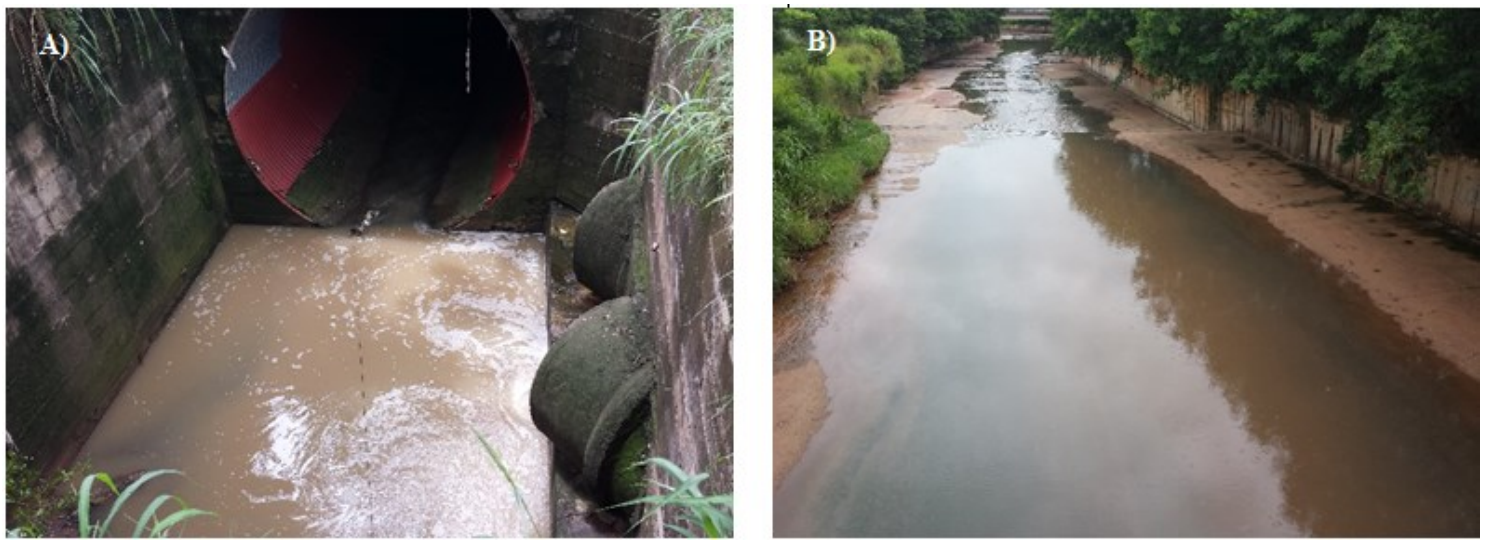

Fonte: AUTOR, 2015.

O ponto P5 está localizado na Estrada Municipal para Coronel Goulart, no Córrego do Limoeiro. Ele é o único ponto que não está inserido na malha urbana, mas está a jusante da Estação de Tratamento de Esgoto (ETE) do município de Presidente Prudente - SP. Esse córrego está em seu leito natural, como pode ser observado na Figura 4.

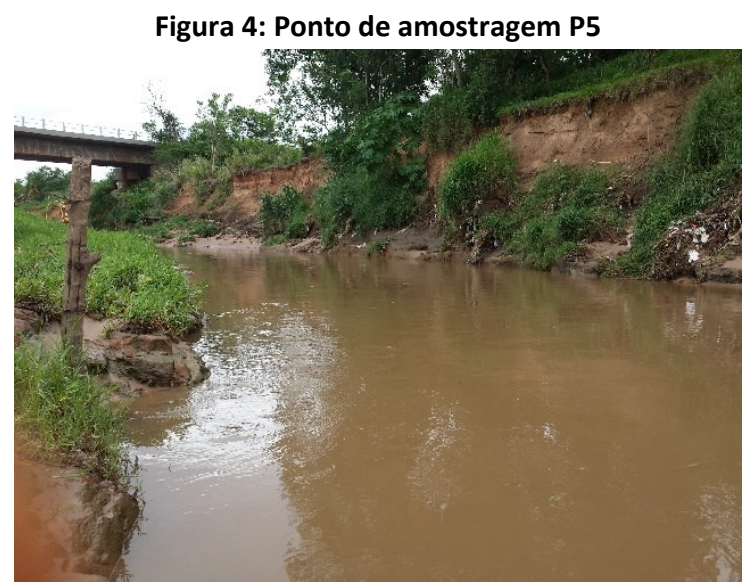

Fonte: AUTOR, 2015.

\subsection{ANÁLISE DA QUALIDADE DE ÁGUA}

As coletas de amostras de água foram realizadas nos seguintes períodos: novembro/2014 (manhã), janeiro/2015 (tarde), março/2015 (tarde), maio/2015 (manhã), julho/2015 (manhã), setembro/2015 (manhã), novembro/2015 (tarde), janeiro/2016 (manhã) e março/2016 (manhã). Nos pontos P2, P3 e P4 a coleta de água foi feita utilizando um balde e uma corda. Já nos pontos P1 e P5, devido à grande facilidade de acesso ao corpo d'água, as amostras foram coletadas diretamente no canal. Em todos os casos, procurou-se coletar a água no leito vazante, na seção central do curso d'água.

As amostras coletadas foram armazenadas em garrafas de Politereftalato de etileno (PET), com capacidade de $2 \mathrm{~L}$, e em recipiente de vidro âmbar, de $250 \mathrm{~mL}$. Ambos foram limpos 


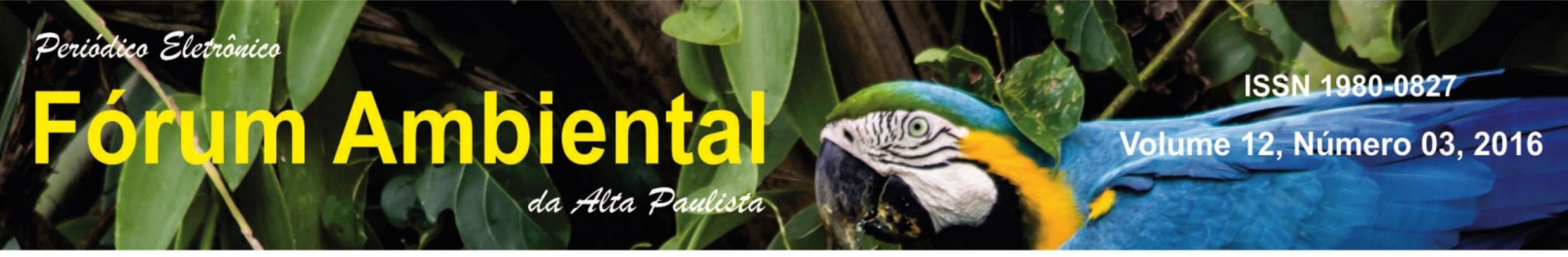

previamente, conforme recomendação da APHA (1998), e acondicionados em uma caixa de isopor com gelo para transporte.

A caracterização da concentração de matéria orgânica nas águas urbanas foi estabelecida por meio das seguintes variáveis: DBO (mg/L), OD (mg/L) e Coliformes Termotolerantes (NMP/100 $\mathrm{mL})$.

As análises seguiram os procedimentos analíticos descritos em APHA (1998), exceto Coliformes Termotolerantes que utilizou o processo de plaqueamento da Petrifilm EC ${ }^{\mathrm{TM}}$ (3M do Brasil Ltda.). As placas $3 \mathrm{M}^{\mathrm{TM}}$ Petrifilm ${ }^{\mathrm{TM}} \mathrm{EC}^{\mathrm{TM}}$ foram utilizadas por se tratar de um método rápido $\mathrm{e}$ eficiente, os resultados são obtidos em cerca de 24 - 48 horas. Diversos estudos confirmam sua eficiência, como por exemplo, no trabalho de Casarotti et al. (2007).

\subsection{ANÁLISE DOS DADOS}

Os dados coletados foram tratados em planilhas eletrônicas para a realização de cálculos e geração de gráficos para a avaliação da qualidade da água. Para isso, foi utilizado o software Microsoft Office Excel ${ }^{\oplus}$.

\section{$4 \quad$ RESULTADOS}

O município de Presidente Prudente - SP merece destaque pela sua demografia por conta de dois dados: o primeiro é que a população estimada em 2015 foi de 222.192 habitantes, o segundo é que a densidade demográfica é de 368,89 habitantes $/ \mathrm{km}^{2}$ (IBGE, 2015a). Para se ter uma ideia o quanto esse valor é expressivo, no Estado de São Paulo a densidade demográfica é de 166,23 habitantes/ $\mathrm{km}^{2}$ (IBGE,2015b).

Em relação à geologia da área de estudo localizada em Presidente Prudente, verifica-se o domínio da Formação Adamantina, pertencente ao Grupo Bauru, localizado na Bacia do Paraná (SOARES, 2012; NUNES, 2002). De acordo com o Instituto de Pesquisas Tecnológicas (IPT) (1981a), esse domínio é constituído por: "Arenitos finos e muito finos, podendo apresentar cimentação e nódulos carbonáticos com lentes de siltitos arenosos e argilitos ocorrendo em bancos maciços, estratificação plano-paralela e cruzada de pequeno a médio porte.".

Geomorfologicamente, Presidente Prudente encontra-se no Planalto Ocidental Paulista (IPT, 1981b), possuindo como principais características o relevo levemente ondulado, predominando colinas amplas e baixas com topos aplanados (ROSS E MOROZ, 1993).

O clima da região onde se encontra a bacia hidrográfica do Limoeiro, de acordo com a classificação climática de Köppen, é do tipo "Aw" (clima tropical com estação de seca no inverno), havendo como característica a temperatura do mês mais frio ser maior que $18 \stackrel{\circ}{ } \mathrm{C}$, e do mês mais quente ser superior a 22 ㄷ, com estação chuvosa no verão e seco no inverno (SOARES, 2012).

A região de Presidente Prudente encontra-se no Bioma Mata Atlântica. Esse bioma é caracterizado pela vegetação florestal predominante e relevo diversificado. Ocorre o 


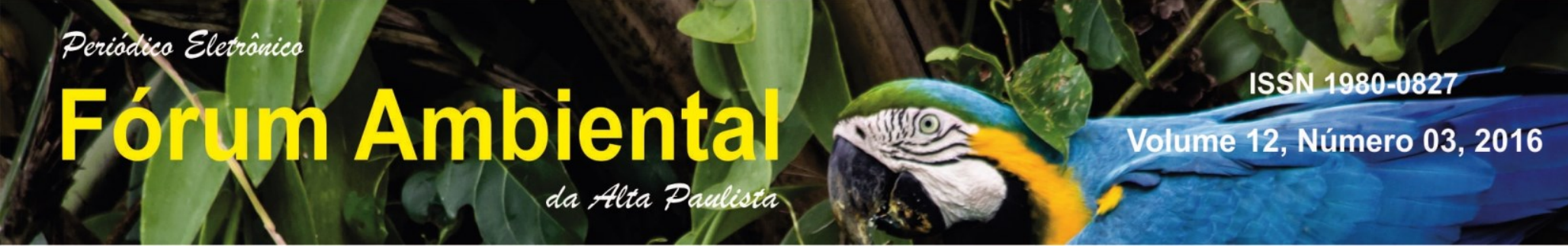

predomínio de florestas estacionárias semideciduais, a principal característica é o fato que 20 a $50 \%$ das árvores perdem as folhas no período seco do ano (IBGE, 2004).

O histórico de ocupação de Presidente Prudente é caracterizado primeiramente pela ocupação dos topos, seguida pela ocupação das vertentes e por último aos fundos de vale. Essa configuração originou sérios problemas ambientais, no qual se pode destacar: aterro de nascentes, ocupação das áreas de proteção permanentes (APPs), elevação do escoamento superficial por conta da impermeabilização do solo, enchentes e inundações por conta das canalizações (fechadas ou abertas) dos cursos d'água e da ocupação irregular, entre outros (SILVA, 2011).

Na Figura 5 é apresentado o comportamento das chuvas ao longo do período de coleta, ou seja, de novembro/2014 a março/2016.

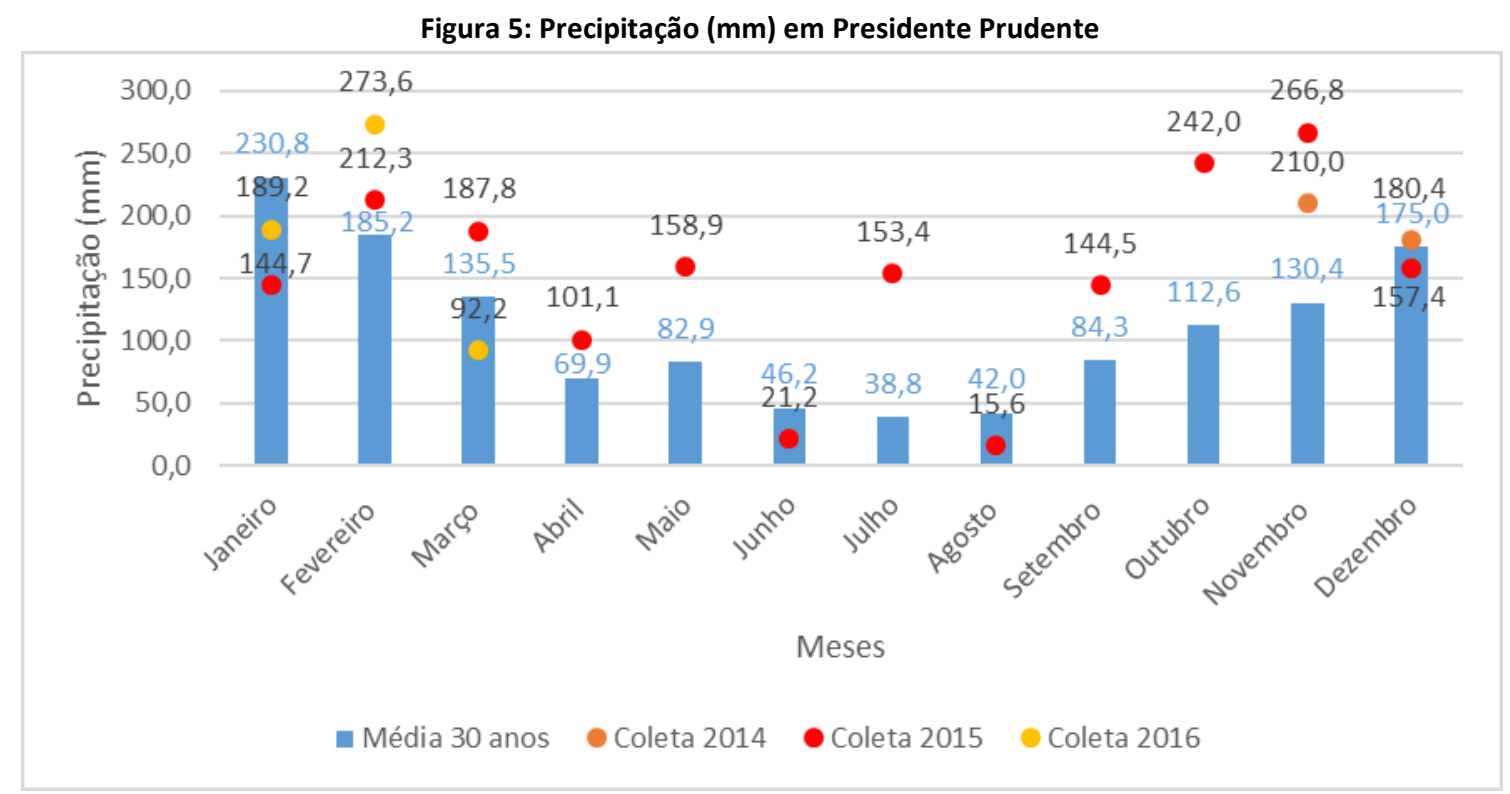

Fonte: ESTAÇÃO METEOROLÓGICA FCT - UNESP, 2016.

Segundo Braido (2010), pode-se considerar, que de acordo a média histórica dessa região, como sendo meses chuvosos: dezembro, janeiro e fevereiro; meses secos: junho, julho e agosto; e, meses com valores habituais os restantes. Quando se compara os valores de precipitação média histórica com o do período de coleta verificou-se que a coleta de janeiro/2015 e março/2016 pode ser classificada como valores habituais. Já a coleta de junho/2015 pode ser classificada como sendo seco, enquanto que as demais podem ser classificadas como sendo chuvoso.

Notou-se que o período de coleta pode ser considerado como atípico, caracterizado como um período muito chuvoso, uma vez que de maneira geral as precipitações mensais se mantiveram acima da média histórica. Entre janeiro/2015 e outubro/2015 a precipitação acumulada ultrapassou os valores anuais de precipitação apresentados pela média histórica. Assim sendo, pode-se considerar o ano de 2015 como sendo um ano chuvoso. 


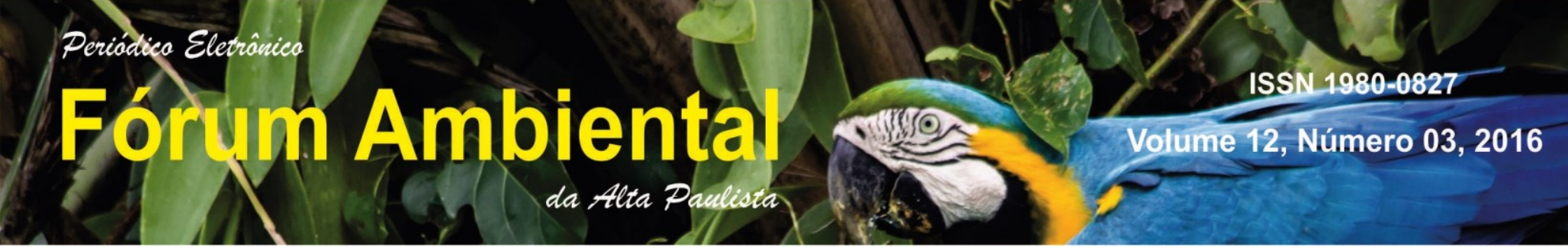

Dessa forma, de forma geral, os resultados desse trabalho foram fortemente influenciados pelos eventos de precipitação, sobretudo no que diz a respeito da poluição difusa, por conta do escoamento superficial.

Os resultados obtidos por meio das análises laboratoriais para a variável DBO estão apresentados na Figura 6.

Figura 6: Variação DBO $(\mathrm{mg} / \mathrm{L})$

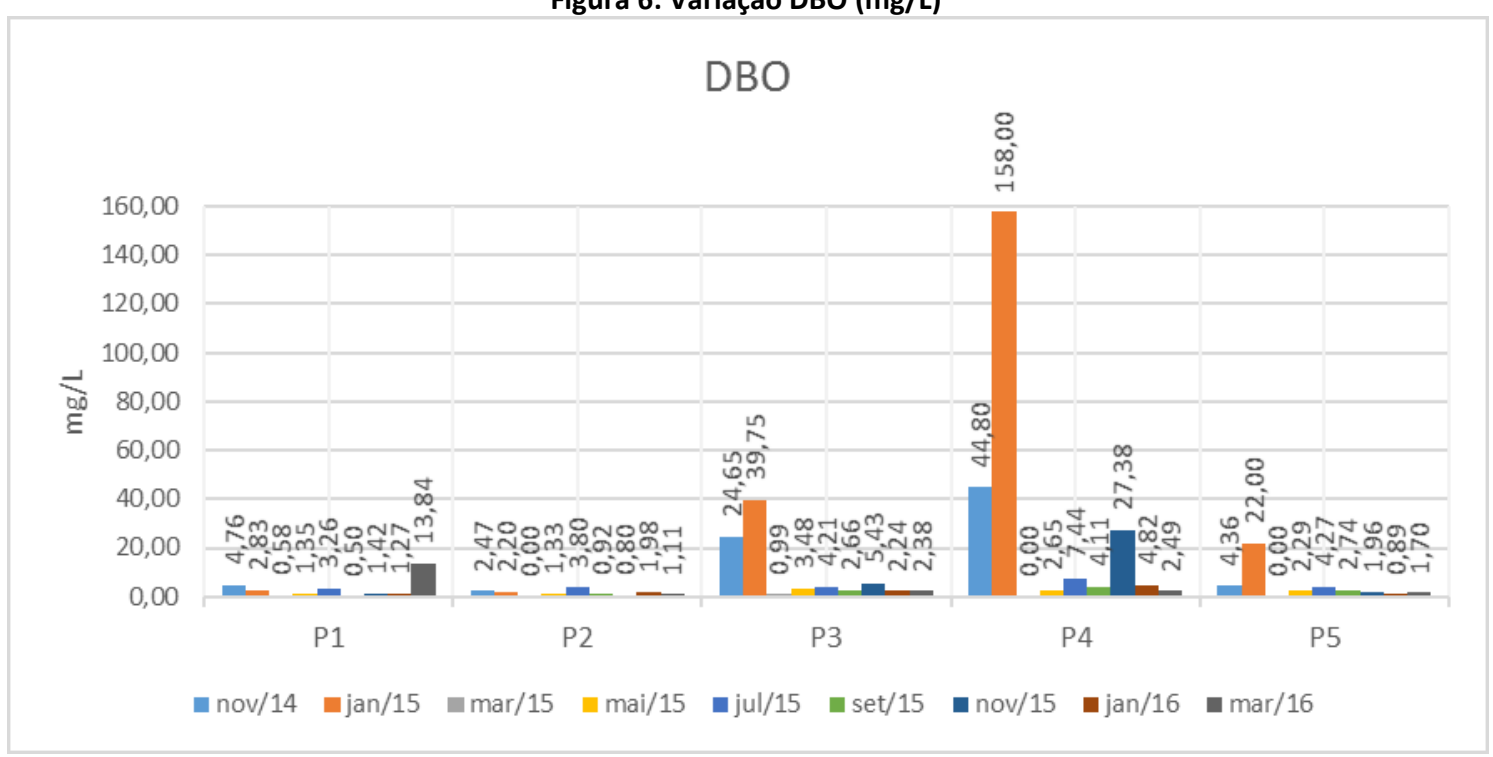

Fonte: AUTOR, 2016.

A DBO avalia a quantidade OD, que será consumida na oxidação biológica da matéria orgânica (PINHO,2001). Dessa forma, representa um dos principais indicadores de qualidade da água, em termos de poluição por matéria orgânica (BARROS, 2008).

A Figura 6 apresenta que os maiores valores de concentração de DBO ocorreram no ponto P4. Muito provavelmente, essas concentrações estão relacionadas ao lançamento de efluentes do curtume e dos frigoríficos no corpo hídrico. De acordo com Braile e Cavalacanti (1993), em média os efluentes de frigoríficos possuem altos valores de DBO oscilando de 800 a 32.000 $\mathrm{mg} / \mathrm{L}$. Esse valor de DBO é bem superior ao encontrado em esgotos domésticos que apresenta valores na faixa de $300 \mathrm{mg} / \mathrm{L}$ (VON SPERLING, 2005).

A Figura 6 mostra também que o ponto P3 apresentou valores de concentração elevados. Acredita-se que seja devido ao lançamento de efluentes domésticos e comerciais sem o devido tratamento, pois houve a constatação de espumas e odor de produtos de limpeza nas coletas amostrais.

Ficou claro que os meses que apresentaram maiores valores para a DBO foram os meses de novembro/2014 e janeiro/2015. Provavelmente isso foi ocasionado por conta do lançamento de efluentes com elevado teor de matéria orgânica no momento da coleta.

Os resultados obtidos por meio das análises laboratoriais para a variável OD estão apresentados na Figura 7. 


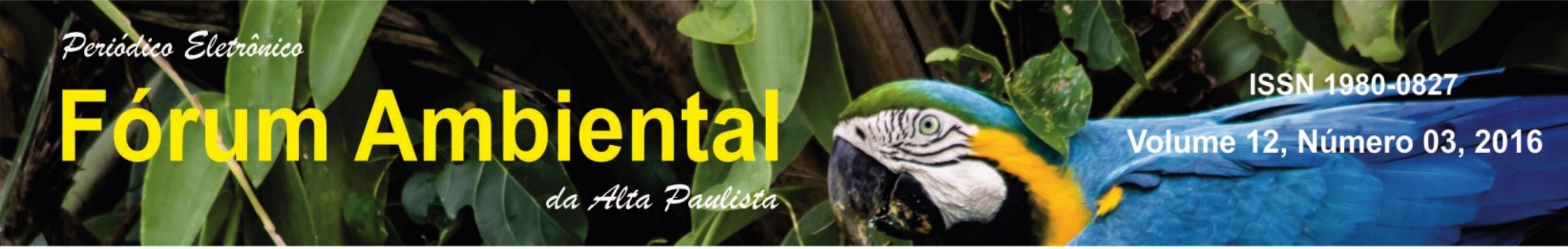

Figura 7: Variação OD (mg/L)

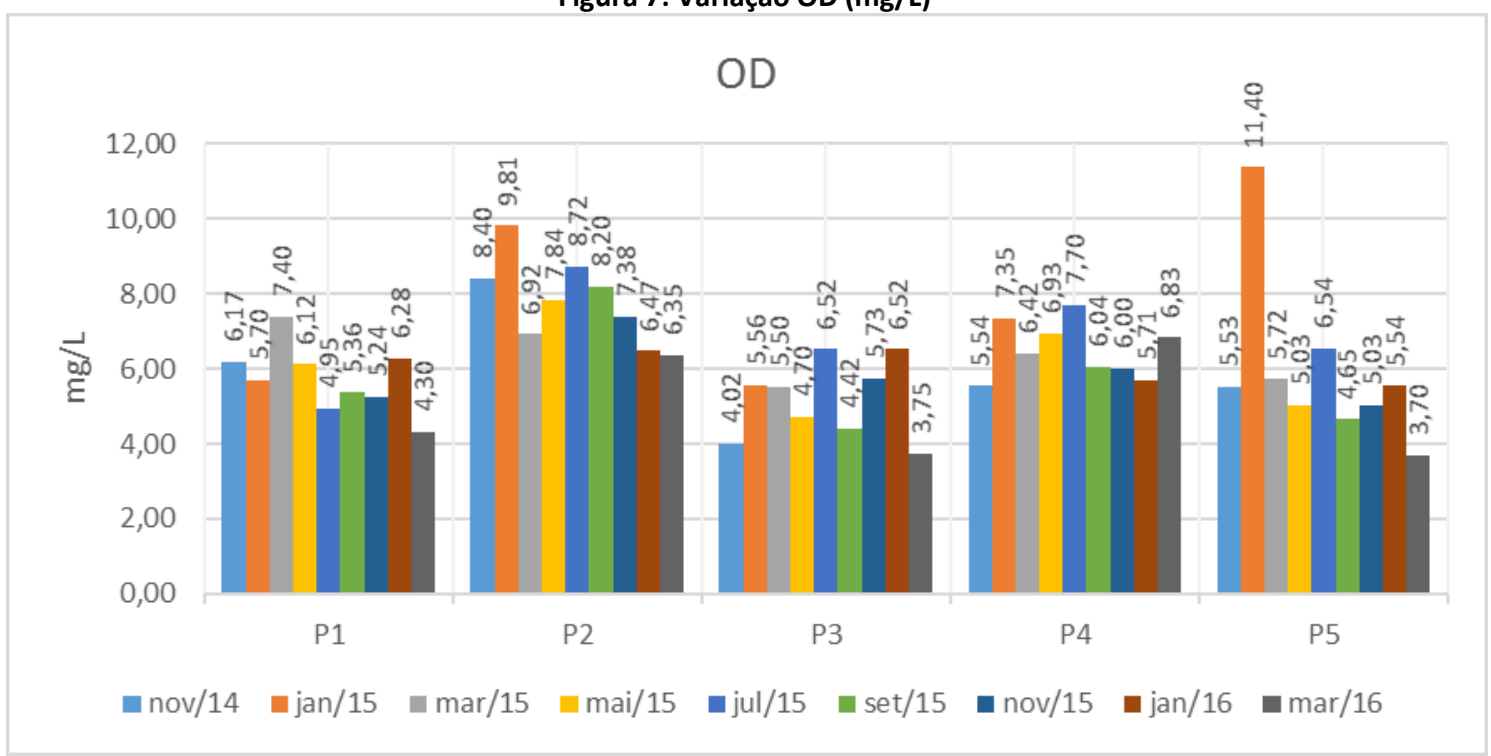

Fonte: AUTOR, 2016.

A presença de OD é vital para os seres aquáticos aeróbicos. As águas poluídas apresentam baixa concentração de $O D$ pois o mesmo é consumido no processo de decomposição da matéria orgânica (ANA, 2016).

De modo geral, a concentração de OD variou de 3,7 a 11,4 mg/L (Figura 7).

A Figura 7 mostra uma concentração de OD baixa principalmente no ponto P3, provavelmente isso se deve ao lançamento de esgotos domésticos e comerciais. Tal ponto apresentou concentrações baixas, independente da época do ano, caracterizando predomínio das fontes de poluição pontual.

O ponto P2, de acordo com a Figura 7, apresentou as melhores condições em relação a esse parâmetro, no qual variou de 6,35 a 9,81 mg/L. Acredita-se que o principal fator que colaborou para esse resultado, foi a existência de degraus no ponto de coleta, promovendo turbulência na água, consequentemente, favorecendo a oxigenação da mesma.

Os resultados obtidos por meio das análises laboratoriais para a variável Coliformes Termotolerantes estão apresentados na Figura 8. 


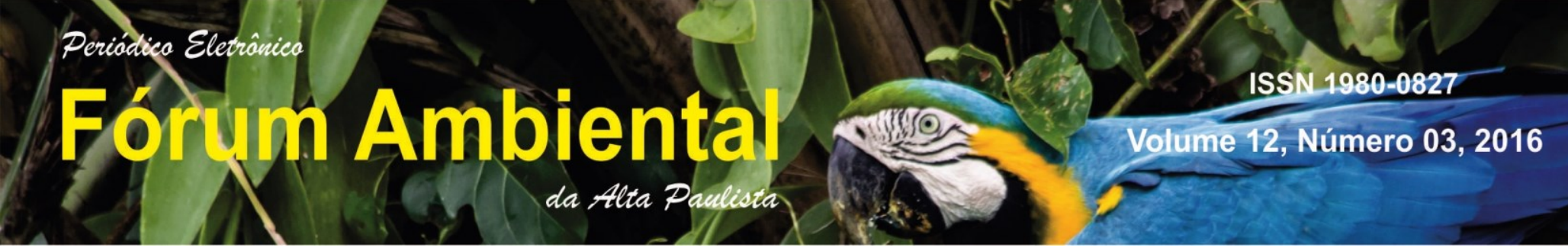

Figura 8: Variação Coliformes Termotolerantes (NMP/100 mL)

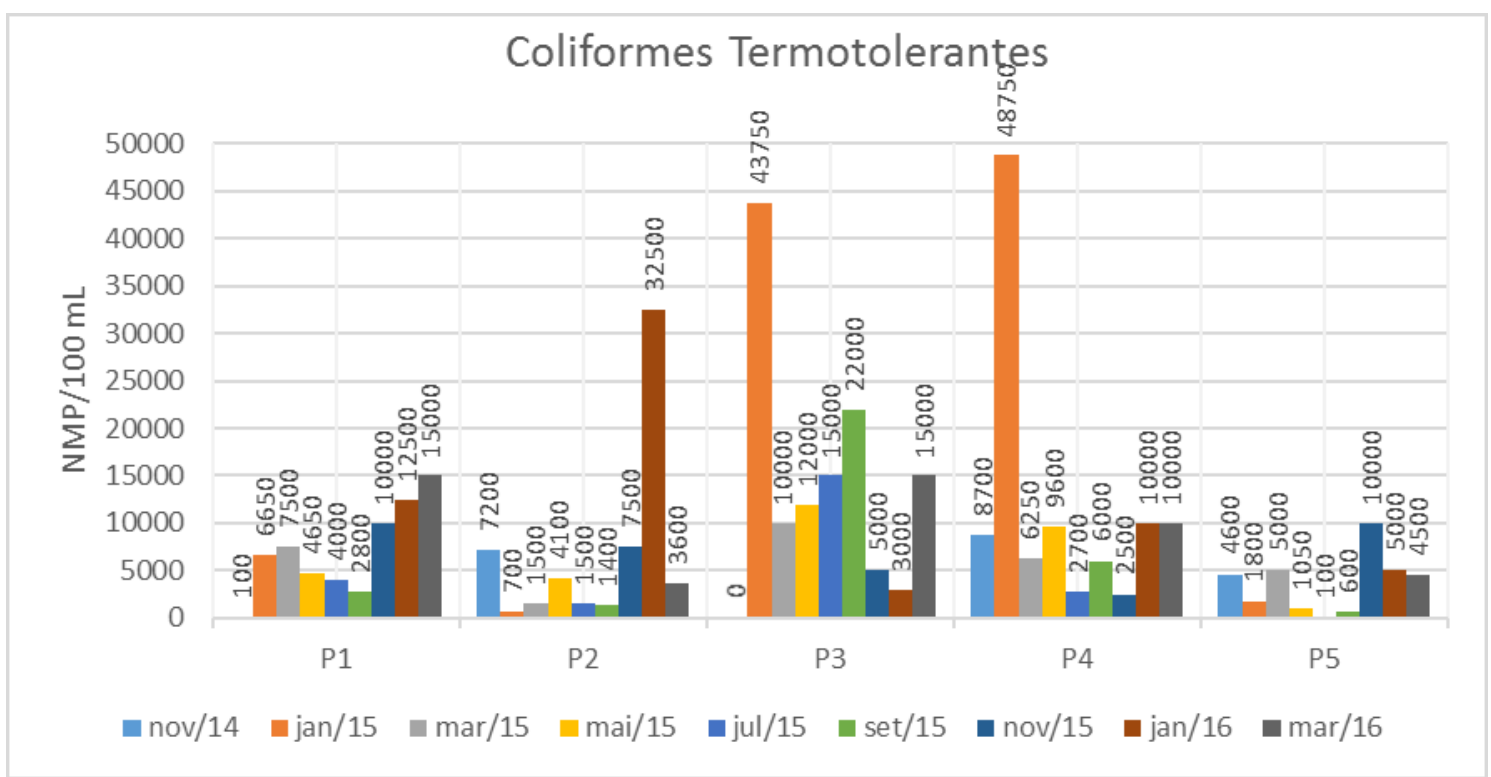

Fonte: AUTOR, 2016.

As bactérias Coliformes Termotolerantes ocorrem no trato intestinal de animais de sangue quente e são indicadoras de poluição por esgotos domésticos. Embora elas não sejam patogênicas, sua presença em elevada quantidade indica a possibilidade da presença de microrganismos patogênicos (ANA, 2016).

A Figura 8 mostra que, de maneira geral, todos os pontos apresentaram elevados valores de Coliformes Termotolerantes, expondo um cenário crítico na bacia hidrográfica, sobretudo os pontos P3 e P4. Acredita-se que isso foi desencadeado pelo lançamento de efluentes domésticos e comerciais, e industriais próximo aos pontos de coleta, respectivamente.

\section{CONCLUSÃO}

Por meio dos resultados obtidos foi verificado que os cursos d'água da bacia hidrográfica do Córrego do Limoeiro estão recebendo elevadas concentrações de matéria orgânica.

Verificou-se existir uma correlação entre os valores de concentração de DBO e Coliformes Termotolerantes, indicando ser diretamente proporcional, validando, assim, o que é apresentado pela literatura. Essa correlação só não foi mais forte devido à complexidade e dinamismo das reações no ambiente natural.

A qualidade da água atestada no presente estudo foi diretamente influenciada pelo uso e ocupação do solo na bacia hidrográfica do Córrego do Limoeiro. Os pontos P1 (nascente) e P2(residencial) foram influenciados principalmente pelas residências circundantes, contudo foram encontradas as melhores condições do estado de qualidade da água. O ponto P3 se encontra em uma situação crítica, sobretudo pelos comércios circundantes a esse ponto de amostragem. Já o ponto P4 foi bastante impactado principalmente pelas indústrias logo a 


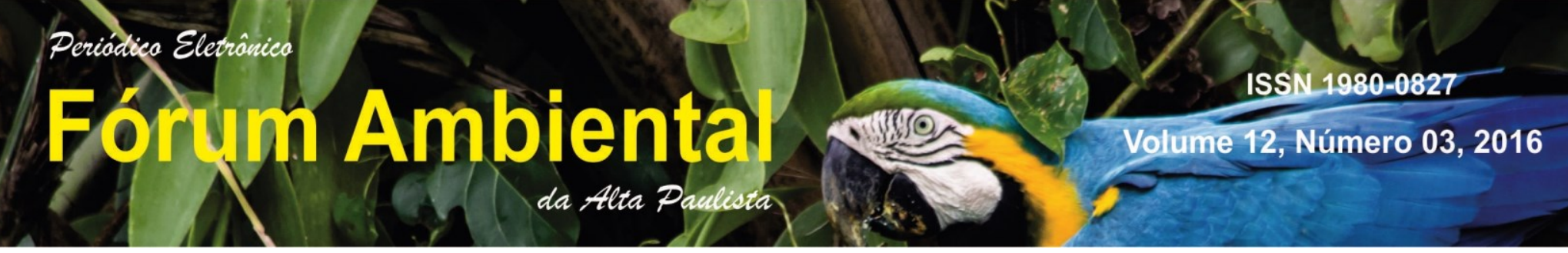

montante desse ponto, sendo dois frigoríficos e um curtume. Por último, tem-se que o ponto P5 foi influenciado pela ETE de Presidente Prudente.

Tendo em vista o apresentado, percebe-se um quadro problemático de poluição das águas da bacia hidrográfica do Córrego Limoeiro, ocasionado danos na qualidade de vida a população. $\mathrm{E}$ se esta pretende possuir água potável no futuro, deve primeiramente rever suas atividades, sejam elas domésticas, comerciais ou industriais, pois todas possuem impactos sobre a qualidade da água.

Portanto, uma maneira de minimizar o problema da poluição é o desenvolvimento de políticas e programas de conscientização, tanto do poder público como da inciativa privada, que elucida que a água é um recurso renovável, mas finito e cada vez mais escasso.

O principal objetivo desse trabalho foi alcançado com excelência, porque por meio dos parâmetros analisados foi possível verificar sua sensibilidade em apresentar alterações ocorridas no meio. Além disso, foi possível identificar os prováveis causadores dessas alterações.

\section{AGRADECIMENTO}

Os autores são gratos à FAPESP, órgão financiador, pela concessão da bolsa de iniciação científica, processo $n^{\circ}$ 2014/18935 - 9, que possibilitou a execução desse trabalho.

\section{REFERÊNCIAS BIBLIOGRÁFICAS}

ANA. Agência Nacional de Águas. Indicadores de Qualidade - Índice de Qualidade das Águas (IQA). 2016. Disponível em: < http://portalpnqa.ana.gov.br/indicadores-indice-aguas.aspx>. Acesso em: 30 mar. 2016.

APHA. American Public Health Association. Standard methods for the examination of water and wastewater. Washington, D.C, 1998.

ARCHELA, E.; CARRARO, A.; FERNANDES, F.; BARROS, O. N. F.; ARCHELA, R. S. Considerações sobre a geração de efluentes líquidos em centros urbanos. Geografia, v. 12, n. 1, p. $517-525$, jan. 2003.

BARROS, A. M. L. Modelagem da poluição pontual e difusa: aplicação do modelo Moneris à Bacia hidrográfica do rio Ipojuca, Pernambuco. 2008. 218f. Dissertação (Graduação em Engenharia Civil) - Centro de Tecnologia e Geociências, Universidade Federal de Pernambuco, Recife.

BNDES. Banco Nacional do Desenvolvimento. Tratamento de esgoto: tecnologias acessíveis. $1997 . \quad$ Disponível em: < http://www.bndes.gov.br/SiteBNDES/export/sites/default/bndes_pt/Galerias/Arquivos/conhe cimento/infra/g7416.pdf>. Acesso em: 30 mar. 2016.

BRAIDO, L. M. H. Caracterização edafoclimática e proposta para a determinação do risco de redução da safra na região do Pontal do Paranapanema - SP. 2010. 125f. Dissertação 


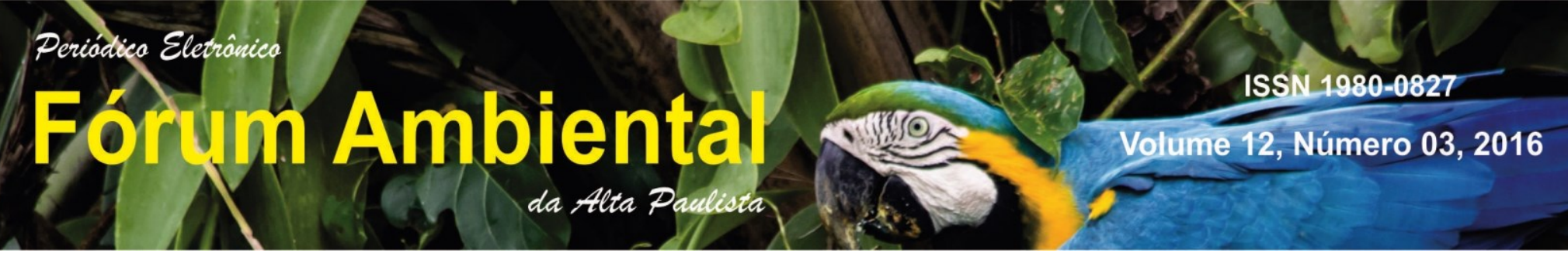

(Mestrado em Geografia) - Faculdade de Ciências e Tecnologia, Universidade Estadual Paulista, Presidente Prudente.

BRAILE, P. M.; CAVALCANTI, J. E. W. A. Manual de Tratamento de Águas Residuárias Industrias. São Paulo: CETESB, 1993.

CAMPOS, Y. O. Gestão ambiental: complexidade sistêmica em bacia hidrográfica. 2010. 187f. Tese (Doutorado em Geografia) - Instituto de Geografia, Universidade Federal de Uberlândia, Uberlândia.

CASAROTTI, S. N.; PAULA, A. T.; ROSSI, D. A. Correlação entre métodos cromogênicos e o método convencional na enumeração de coliformes e Escherichia coli em carne bovina moída. Rev. Unst. Adolfo Lutz, v. 66, n. 3, p. $278-286,2007$.

DINIZ, L. T. Efetivação das Metas de Qualidade de Águas Superficiais no Brasil. 2006. $159 f$. Dissertação (Mestrado em Ciência Ambiental) - Universidade de São Paulo, São Paulo.

HONDA, S. C. A. L; VIEIRA, M. C.; ALBANO, M. P.; MARIA, Y. R. Planejamento ambiental e ocupação do solo urbano em Presidente Prudente (SP). Revista Brasileira de Gestão Urbana, v. 7, n. 1, p. $62-73$, jan. 2015.

IBGE. Instituto Brasileiro de Geografia e Estatística. Cidades@. 2015 (2015a). Disponível em: < http://cidades.ibge.gov.br/xtras/perfil.php?codmun=354140>. Acesso em: 30 mar. 2016.

IBGE. Instituto Brasileiro de Geografia e Estatística. Estados@. 2015 (2015b). Disponível em: < http://www.ibge.gov.br/estadosat/perfil.php?lang=\&sigla=sp>. Acesso em: 30 mar. 2016.

IBGE. Instituto Brasileiro de Geografia e Estatística. IBGE lança o Mapa de Biomas do Brasil e o Mapa de Vegetação do Brasil, em comemoração ao Dia Mundial da Biodiversidade. 2004. Disponível

em:<http://www.ibge.gov.br/home/presidencia/noticias/21052004biomashtml.shtm> Acesso em: 30 mar. 2016.

INSTITUTO DE PESQUISAS TECNOLÓGICAS DO ESTAdO DE SÃO PAULO (IPT). Mapa geomorfológico do Estado de São Paulo: 1:1.000.000. São Paulo: IPT, vol. II, 1981b, p. 6; 7; 21; 70-2 (Publicação IPT 1183).

INSTITUTO DE PESQUISAS TECNOLÓGICAS DO ESTADO DE SÃOPAULO (IPT). Mapa geológico do Estado de São Paulo: 1:500.000. São Paulo: IPT, vol. I, 1981a, p. 46-8; 69 (Publicação IPT 1184).

INSTITUTO DE PESQUISAS TECNOLÓGICAS DO ESTADO DE SÃO PAULO (IPT). Diagnóstico da situação atual dos recursos hídricos e estabelecimento de diretrizes técnicas para a elaboração do plano da bacia hidrográfica do Tietê - Jacaré. São Paulo: 2000 (Publicação IPT 40674).

LEITE, A. E. B. Simulação do lançamento de esgotos domésticos em rios usando um modelo de qualidade d'água, SisBAHIA ${ }^{\circledR}$. 2004. 94f. Dissertação (Mestrado em Saúde Pública) - Escola Nacional de Saúde Pública, Fiocruz, Rio de Janeiro. 
